\title{
Non-allergic activation of eosinophils after strenuous endurance exercise
}

\author{
A J McKune (MMedSci) ${ }^{1}$ \\ L L Smith (PhD) ${ }^{1}$ \\ S J Semple (MTech) ${ }^{1}$ \\ A A Wadee $(\mathrm{PhD})^{2}$
}

'Department of Sport and Physical Rehabilitation Sciences, Tshwane University of Technology, Pretoria

${ }^{2}$ Department of Immunology, University of the Witwatersrand and the National Health Laboratory Service, Johannesburg

\begin{abstract}
Objective. To determine the effect of prolonged endurance exercise on the serum concentrations of eosinophil cationic protein (ECP), immunoglobulin E (IgE) and upper respiratory tract symptoms (URTS).

Design. In 11 healthy, experienced volunteers ( 6 males, 5 females, age $43 \pm 9.8$ years) the serum concentrations of ECP and IgE were measured, 24 hours prior to projected finishing time, immediately post exercise (IPE), and $3 \mathrm{~h}$, $24 \mathrm{~h}$, and $72 \mathrm{~h}$ after an ultramarathon $(90 \mathrm{~km})$. Self-reported URTS were also recorded for 14 days after the race. ECP was measured using radioimmunoassay and IgE using the Alastat Microplate Total IgE kit. The after-exercise values were corrected for plasma volume changes, which were calculated from haematocrit and haemoglobin values. Serum concentrations of ECP and $\lg E$ were analysed using an analysis of variance (ANOVA) comparing values with before-exercise levels. Level of significance was set at $p \leq 0.05$.

Results. ECP was significantly elevated at 72 hours $(+52 \%)$, whilst IgE was not significantly altered after the ultramarathon. There were no reported URTS for the 14 days after the race.

Conclusion. The eosinophil is a pro-inflammatory leukocyte involved in bronchial hyperreactivity and allergic inflammation of the airways. IgE is associated with allergic diseases such as asthma and rhinitis. Serum ECP is a sensitive marker of eosinophil activation. The result provides evidence for the non-allergic activation of blood
\end{abstract}

\section{CORRESPONDENCE:}

\author{
A J McKune \\ Private Bag X680 \\ Pretoria \\ 0001 \\ Tel: 012-318 4442 \\ Fax: 012-318 5801 \\ E-mail: mckunea@techpta.ac.za
}

eosinophils during prolonged endurance exercise Whether this indicates exercise or environmentally induced airway inflammation, or a role for ECP in muscle /tissue repair, are hypotheses that require additional research.

\section{Introduction}

Strenuous endurance exercise and long-term endurance training are associated with muscle adaptations and damage, with reports of ultrastructural and morphological changes ${ }^{2,9,15}$ as well as a systemic inflammatory response..$^{39}$ Research has reported mobilization and activation of neutrophils, ${ }^{4,19}$ heightened leucocyte turnover, ${ }^{4}$ and a complex pattern of pro- and anti-inflammatory cytokine release related to muscle or tissue damage. ${ }^{27,41}$ Whether strenuous endurance exercise affects the airway and systemic compartments similarly, and the possibility that it may cause adpatations or damage at the airway level, are issues that require further research.

It has been shown that strenuous endurance exercise affects the airways by increasing the incidence of upper respiratory tract infections (URTIs) related to bacterial or viral infections ${ }^{26,29}$ and respiratory symptoms such as exerciseinduced bronchoconstriction (EIB) $)^{1,16}$ or airway hyperresponsiveness (AHR). ${ }^{22,33}$ Whilst immunosuppression has been related to the increase in URTIs, ${ }^{21}$ studies on airway cells and inflammatory markers in endurance athletes have suggested a possible association between airway inflammatory cells and exercise-induced respiratory symptoms. ${ }^{5}$ Recently, it was found that common viral and bacterial agents as well as allergy/asthma were not responsible for upper respiratory tract symptoms (URTS) reported 2 - 10 days after an ultramarathon race. ${ }^{37}$ The results suggested that the URTS symptoms may be due to mucosal inflammation in the upper respiratory tract (URT), although airway inflammatory cells and markers were not measured.

Eosinophils have been recognised as URT pro-inflammatory cells with a considerable tissue-injuring potential, ${ }^{42}$ and have been shown to mediate damage to respiratory epithelium as well as shedding of bronchial epithelium leading to tissue damage. ${ }^{17}$ Eosinophil cationic protein $(E C P)$ is an eosinophil granule-derived protein and serum ECP is regarded as a highly sensitive marker of eosinophil activation in the 
URT. ${ }^{43}$ ECP plays an important role in the pathogenesis of URT allergic inflammation ${ }^{11}$ and asthma, where it is released in response to allergen-immunoglobulin $\mathrm{E}$ (IgE) crosslinking. ${ }^{14}$ Recently, it was reported that a dietary deficiency of antioxidant vitamins may play a role in increasing the severity of asthma. ${ }^{24}$ Bowler amd $\mathrm{Crapo}^{6}$ suggested that augmentation of existing antioxidant defences with catalytic antioxidants might be useful in attenuating respiratory disorders through counteracting the effects of inflammatory cells such as airway eosinophils. Similarily, it has been reported that antioxidant supplementation may reduce the incidence of URTI after ultramarathon running ${ }^{30}$ However, Bowler and Crapo $^{6}$ concluded that the use of antioxidants in the treatment of airway reactions requires further study. Recently, it was shown that the use of airway anti-inflammatory medication reduced the self-reported incidence of URTS in ultramarathon runners. ${ }^{36}$

Only two previous studies have reported that eosinophils may be activated by non-allergic mechanisms in healthy subjects. Both prolonged endurance exercise ${ }^{11}$ and short-term maximal exercise ${ }^{12}$ were shown to increase serum ECP in healthy subjects. There is therefore, limited data on the response of eosinophils to a physiological challenge such as endurance exercise, and the possibility that these cells may be associated with the URTS reported after endurance exercise in non-allergic/asthmatic individuals is yet to be explored. The aim of the study was therefore to monitor eosinophil activation by measuring serum ECP, a possible allergic involvement through measuring alterations in serum $\lg \mathrm{E}$, and the association that alterations in these serum proteins may have with URTS after an ultramarathon.

\section{Methods}

\section{Subjects}

Eleven experienced runners ( 6 males, 5 females) from local running clubs and who had entered the 2002, $90 \mathrm{~km}$ Comrades ultramarathon, volunteered to participate in this study.

\section{Exclusion criteria}

Subjects who reported that they smoked or suffered from asthma, allergic rhinitis, respiratory disease or had an URTI in the week leading up to the ultramarathon were excluded. The protocol was approved by the Tshwane Institute of Technology Ethics Committee, and informed consent was obtained from each subject.

\section{Medication and nutritional supplements}

Subjects were asked to abstain from the use of anti-inflammatory and anti-histamine medication. The use of multivitamins and anti-oxidants was not controlled. However, the subjects recorded their dietary and supplement intake for 2 weeks before and 2 weeks after the Comrades to help control for the possible effect of multivitamin and anti-oxidant intake on results.

\section{Study design}

The subjects reported to the exercise testing laboratory 2 weeks before the race where they completed questionnaires relating to their health history, training schedule (distance run in the past 6 months), and ultramarathon experience. Following completion of the questionnaires, body composition and cardiorespiratory fitness were determined.

\section{Body composition}

Height and weight were recorded using a calibrated medical height gauge and balance scale (Detecto, Webb City, USA). A Harpenden skinfold caliper was used for skinfold measurements ( 7 sites) to assess body composition using the Drinkwater-Ross method. ${ }^{34}$

\section{Maximal oxygen uptake and heart rate}

Subjects were instructed to abstain from high-intensity or long-duration training sessions the day prior to being tested. In addition they were instructed to eat a light meal three hours prior to the $\mathrm{VO}_{2 \max }$ testing. The test was performed on a Quinton 90 treadmill (Quinton Instrument Co., Seattle, Washington). Continuous respiratory measurements were recorded by means of the MedGraphics $\mathrm{CardiO}_{2}$ combined $\mathrm{VO}_{2}$ /ECG exercise system (Medical Graphics Corporation, Chicago, Illinois). Heart rate response was monitored using a Polar Heart rate monitor. The test began at $8 \mathrm{~km} / \mathrm{h}$ on a $3 \%$ incline, for 5 minutes. Thereafter, speed and gradient were increased at $1 \mathrm{~km} / \mathrm{h}$ and $1 \%$ respectively every minute. From $12 \mathrm{~km} / \mathrm{h}$, only the gradient was increased by $1 \%$ per minute until exhaustion. ${ }^{23}$ Standard criteria were used to ensure attainment of $\mathrm{VO}_{2 \max .}{ }^{32}$

\section{Ultramarathon testing \\ Upper respiratory tract symptoms}

Twenty-four hours prior to the projected finishing time the runners completed a questionnaire on their state of health during the 2 weeks leading up to the race. For 2 weeks after completion of the race the subjects completed a daily questionnaire regarding the severity and duration of URTS. The questionnaire included a scale which assessed the severity and duration of self-reported URTS such as a running nose, sneezing, sore throat, and cough..$^{29}$

\section{Blood draws}

Venous blood samples $(15 \mathrm{ml})$ were collected 24 hours prior to projected finishing time, and then within 10 minutes immediately post exercise (IPE), and $3 \mathrm{~h}, 24 \mathrm{~h}$, and $72 \mathrm{~h}$ after the ultramarathon. Five millilitres of blood were collected in glass vacutainer tubes containing the anticoagulant, tripotassium ethylenediaminetetraacetic acid ( $k_{3}$-EDTA) and were used to determine full blood counts. Ten millilitres were collected in serum separator tubes which remained at room temperature for 30 minutes. These tubes were then centrifuged for 10 minutes and the serum was divided into $0.5 \mathrm{ml}$ aliquots and stored at $-80^{\circ} \mathrm{C}$ until analysis.

\section{Haematological adjustments}

Full blood counts were performed on k3-EDTA-treated specimens using standard haematological procedures on an automated STKS model (Coulter Electronics Inc., Hialeah, Florida, USA). Plasma volume changes were determined from pre- and post-race haemoglobin and haematocrit values using the method of Dill and Costill. ${ }^{10}$ 


\section{Determination of ECP and IgE}

Serum ECP concentrations were determined using a radioimmunoassay technique (ECP-RIA, Pharmacia, Stockholm, Sweden) as described by Peterson et al. ${ }^{31}$ Serum ECP was considered normal within the range of 2 - $15 \mu \mathrm{g} / \mathrm{l}$. The total serum IgE (normal range, 22 - $86 \mathrm{KU} / \mathrm{I}$ ) was determined with the use of the Alastat Microplate Total IgE kit (Diagnostic Products, USA) according to the manufacturer's instructions and by comparison with a known range of standard $\lg \mathrm{E}$ concentrations. High and low control samples were run for both assays, and all samples were analysed in triplicate. To avoid inter-assay variability, all samples from each subject were assayed on the same microtitre plate.

\section{Statistical analysis}

Results are expressed as means \pm SE. Data were analysed using commercial software (SAS Institute, Cary, NC) using an analysis of variance (ANOVA), contrasting variables to baseline values. Tukey's post hoc tests were use to determine significant differences attributed to time. The level of significance was set at $p<0.05$.

\section{Results}

\section{Subjects}

Demographic data on the runners are shown in Table I. The subjects in the study were experienced ultramarathon runners having completed an average of 4 ultramarathons. The average distance covered in training in preparation for the ultramarathon was $1377.3 \mathrm{~km}$ (January - June). The average time taken to complete the race $(9.45 \mathrm{~h} \pm 1.1)$ indicates that the athletes were not in the elite category. The cut-off time for the race is 11 hours, with the top 10 runners usually completing the $90 \mathrm{~km}$ under 6 hours. There were no reports of URTS in the 2 weeks prior to or after the ultramarathon. The dietary and supplement records did not reveal excessive intake of multivitamins or anti-oxidants.

\section{Serological parameters}

The before and after-race levels of ECP (normal < $15 \mathrm{ug} / \mathrm{l}$ ) and IgE (normal range 22 - $85 \mathrm{KU} / \mathrm{l}$ ) were within clinically normal reference ranges. All after-race exercise concentrations of ECP and IgE were corrected for exercise-induced plasma volume changes before statistical analysis.

Eosinophil cationic protein level began rising immediately after the ultramarathon. Fig. 1 shows that the ECP level was significantly increased $(+52 \%)$ at $72 \mathrm{~h}(p=0.03)$ compared

\begin{tabular}{|ll|}
\hline TABLE I. Subject characteristics \\
\hline Parameter & Mean ( \pm SD) \\
\hline Age (years) & $43( \pm 10)$ \\
Height $(\mathrm{cm})$ & $170( \pm 10)$ \\
Weight $(\mathrm{kg})$ & $64( \pm 13)$ \\
Body fat $(\%($ & $14( \pm 3)$ \\
$\mathrm{VO}_{2 \text { max }}(\mathrm{ml} / \mathrm{kg} / \mathrm{min})$ & $57.5( \pm 6)$ \\
$\mathrm{HR}_{\max }($ beats/min) & $172( \pm 15)$ \\
Weekly training distance $(\mathrm{km} / \mathrm{wk})$ & $58( \pm 17)$ \\
Race time (hours) & $9.45( \pm 1.1)$ \\
\hline
\end{tabular}

with the before-exercise level. There was no significant alteration in $\lg E$ concentration after the ultramarathon (Fig. 2).

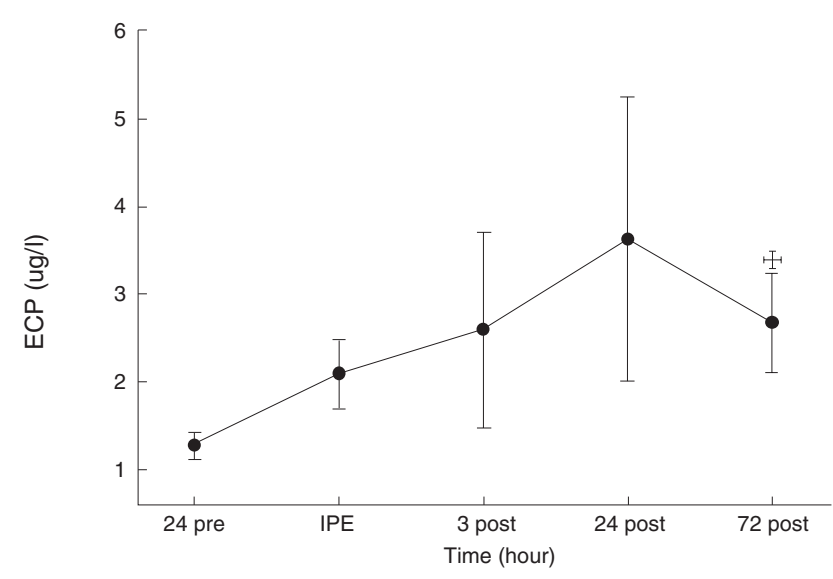

Fig. 1. Alterations in serum eosinophil cationic protein ( $\mu$ gll) of 6 male and 5 female subjects following an ultramarathon. Signifies $p<0.05$ compared with before race levels.

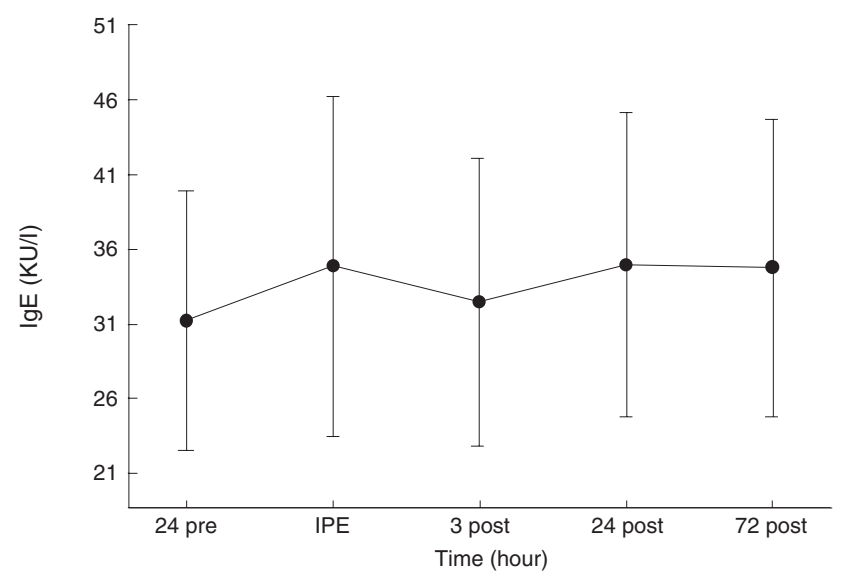

Fig. 2. Alterations in serum immunoglobulin $E$ (KUII) of 6 male and 5 female subjects following an ultramarathon.

\section{Discussion}

Strenuous endurance exercise causes significant stress to the respiratory system, from the associated hyperventilation, as well as increased airway exposure to contaminants of inhaled air ${ }^{3,7,25,40}$ such as allergens or pollutants. ${ }^{18}$ URTS have been linked with bacterial or viral infection during an 'openwindow period', 3 - 72 hours after exercise where an individual is susceptible due to exercise-induced immunosuppression. ${ }^{21}$ Recently, it was hypothesised that URTS after an ultramarathon may not be due to bacterial or viral infection or allergy, ${ }^{37}$ with the results suggesting that mucosal URT inflammation may be the source of URTS. The present study investigated the effects of an ultramarathon on immune parameters, which could be associated with postexercise URTS. 
Eosinophil cationic protein was significantly increased 72 hours after the ultramarathon (Fig. 1) whilst IgE was not significantly altered (Fig. 2). These data suggest a non-allergic activation of blood eosinophils after strenuous endurance exercise. Recently, a similar elevation in serum ECP was reported to provide evidence for a moderate generation of bronchial hyperreactivity in healthy individuals after prolonged endurance exercise. ${ }^{11}$ A subclinical, non-allergic inflammation associated with eosinophil activation within the airways was suggested to be responsible for the increase in bronchial reactivity. ${ }^{11}$ It was proposed that intense prolonged mouth breathing of cold, dry air during exercise might have been responsible for increased respiratory water loss and subsequent osmotic challenge to the bronchial epithelium. Damaged epithelial cells might then have attracted circulating eosinophils to the airway mucosa via the release of the cytokines interleukin-5 (IL-5) and tumour necrosis factor- $\alpha$. These eosinophils subsequently degranulated with the release of ECP, which caused further damage and inflammation in the respiratory epithelium. ${ }^{11}$ This is a possible explanation for the raised serum ECP in the present study.

Although bronchial hyperactivity was not measured and there were no reported clinical URTS for the 2 weeks after the ultramarathon, the raised serum ECP levels in both studies suggest the possibility that an acute bout of strenuous endurance exercise may cause weak mucosal URT inflammation. This inflammation may be similar in nature to that found in a process called 'minimal persistent inflammation' (MPI) that has been demonstrated in both mite-induced and pollen-induced rhinitis ${ }^{8}$ and asymptomatic allergic subjects. ${ }^{28}$ Although the URTS questionnaire has been used successfully in the past to identify URTS ${ }^{30}$ it is possible that a more sensitive questionnaire is required to identify self-reported symptoms/manifestations of minimal airway inflammation. The questionnaire used was biased towards URTI symptoms and therefore a future study should look at validating a questionnaire that is sensitive to symptoms of airway inflammation. An additional explanation for the lack of reported URTS is the small sample size. A larger sample size may have increased the probability of more subjects with URTS. The authors therefore do not rule out the possibility of URTS related to the presence of ECP in the present study. Whether frequent episodes of such non-allergic ECP peaks create a higher risk in healthy individuals for developing exerciseinduced and allergic asthma/rhinitis over time, or increased after-exercise reporting of URTI-like symptoms, are questions that remain unanswered.

Short maximal exercise has also been shown to cause a non-allergic activation of eosinophils in healthy individuals. Plasma ECP was shown to be elevated immediately after a graded maximal bicycle exercise test. ${ }^{12}$ Two possible explanations for eosinophil activation were provided which are related to exercise-induced muscle/tissue damage. Firstly, that ECP is usually released by eosinophils to deal with nonphagocytosable opsonised micro-organisms (e.g. parasites). ${ }^{20}$ It was speculated that during strenuous exercise non-phagocytosable muscle/tissue fragments are liberated accounting, in analogy to the defence against parasites, for the eosinophil activation and ECP release. The second explanation was that ECP has been shown to participate in muscle/tissue repair processes by modifying the production of glycosaminoglycans by human fibroblasts. ${ }^{35}$ These two explanations are feasible for the present study as strenuous endurance exercise has been reported to cause muscle / tissue damage $e^{2,9,15,41}$ that requires removal and repair. The acute phase response (APR) to muscle/tissue damage, specifically the activation of complement components C3, C4 and C5 fragments, may be a possible mechanism for activating eosinophils. ${ }^{13}$ Submitted data from the present study have shown that the same ultramarathon caused an APR and an increase in complement, ${ }^{38}$ and this may have played a role in the non-allergic activation of eosinophils.

\section{Conclusions}

The finding that ECP was elevated after the ultramarathon leads to various hypotheses that require testing. Firstly, that non-allergic eosinophil activation is maladaptive and that frequent episodes of subclinical exercise-induced ECP peaks in healthy individuals might result in MPI and the development of exercise-induced or allergic asthma/rhinitis. Secondly, that non-allergic eosinophil activation represents a normal physiological adaptive response of the immune system to the presence of non-phagocytosable muscle/tissue fragments and that eosinophils are activated to assist with removal and repair. Thirdly, that the URTS reported after exercise by individuals may not be the result of infection but rather due to mucosal URT inflammation induced by activated inflammatory cells in the URT. Further studies are therefore necessary to test these hypotheses and at the same time aim to determine, in terms of inflammatory processes in the URT: (i) the exercise dose-response; (ii) the role of environmental factors in determining different airway cell patterns; (iii) the timecourse and features of training-induced adaptations, and (iv) long-term effects of exercise training, and their possible impact on respiratory health. ${ }^{5}$

\section{Acknowledgements}

This research was supported by grants from the Faculty of Health Sciences, Tshwane University of Technology and the National Research Foundation, Thuthuka Programme, South Africa.

\section{REFERENCES}

1. Anderson SD, Daviskas $E$. The mechanism of exercise-induced asthma is... J Allergy Clin Immunol 2000;106: 453-9.

2. Armstrong R. Muscle damage and endurance events. Sports Med 1986 ; 3: $370-81$

3. Barnes PJ, FitzGerald GA, Dollery CT. Circadian variation in adrenergic responses in asthmatic subjects. Clin Sci 1982; 62: 349-54.

4. Bonsignore MR, Morici G, Santoro A, et al. Circulating hematopoietic progenitor cells in runners. J Appl Physiol 2002; 93: 1691-7.

5. Bonsignore MR, Morici G, Vignola AM, et al. Increased airway inflammatory cells in endurance athletes: what do they mean? Clin Exp Allergy 2003; 33: 14-21.

6. Bowler P, Crapo JD. Oxidative stress in allergic respiratory diseases. $J$ Allergy Clin Immunol 2002; 110: 349-56.

7. Camus G, Dupont-Deby G, Duchateau J, Deby C, Pincemail J, Lamy M. Are similar inflammatory factors involved in strenuous exercise and sepsis. Intensive Care Med 1994; 20: 602-10.

8. Ciprandi G, Buscaglia S, Pesce GP, et al. Minimal persistent inflammation is present at mucosal level in asymptomatic rhinitic patients with allergy due to mites. J Allergy Clin Immunol 1995; 96: 971-9.

9. Derman EW, Schwellnus M, Lambert MI, et al. The 'worn-out' athlete: a 
clinical approach to chronic fatigue in athletes. J Sports Sci 1997;15: 34151.

10. Dill DB, Costill DL. Calculation of percentage changes of blood, plasma and red cells in dehydration. J Appl Physiol 1974; 37: 247-8.

11. Domej W, Schwaberger G, Tilz GP, et al. Prolonged endurance challenge at moderate altitude. Effect on serum eosinophil cationic protein, eosinophil dynamics, and lung function. Chest 2002; 121: 1111-6.

12. Dufaux B, Heine O, Prinz U, Soll C, Rost R. Effect of short maximal physical exercise on the eosinophil cationic protein. Int J Sports Med 1993; 14: 468-70.

13. Dufaux B, Order U. Complement activation after prolonged exercise. Clin Chim Acta 1989; 179: 45-50.

14. Erjefalt JS, Greiff L, Andersson M, et al. Allergen-induced eosinophil cytolysis is a primary mechanism for granule protein release in human upper airways. Am J Respir Crit Care Med 1999; 160: 304-12.

15. Fielding RA, Manfredi TJ, Ding W, Fiatarone MA, Evans WJ, Cannon JG. Acute phase response in exercise III. Neutrophil and IL-1b accumulation in skeletal muscle. Am J Physiol 1993; 265: R166-72.

16. Freed AN. Models and mechanisms of exercise-induced asthma. Eur Respir J 1995; 8: 1770-85.

17. Gleich GJ, Flavahan NA, Fujisawa T, Vanhoutte PM. The eosinophil as a mediator of damage to respiratory epithelium: a model for bronchial hyperreactivity. J Allergy Clin Immunol 1988; 81: 776-81.

18. Helenius IJ, Tikkanen HO, Sarna S, Haahtela T. Asthma and increased bronchial responsiveness in elite athletes: atopy and sport event as risk factors. J Allergy Clin Immunol 1998; 101: 646-52.

19. Jordan J, Beneke R, Hutler M, Veith A, Luft FC, Haller H. Regulation of MAC-1 (CD11b/CD18) expression on circulating granulocytes in endurance runners. Med Sci Sports Exerc 1999; 31: 362-7.

20. Kay AB. Biological properties of eosinophils. Clin Exp Allergy 1991; 21: Suppl 3, 23-9.

21. Mackinnon LJ. Advances in Exercise Immunology. Champaign, Illinois: Human Kinetics, 1999.

22. Mannix ET, Farber MO, Palange P, Galassetti P, Manfredi F. Exerciseinduced asthma in figure skaters. Chest 1996; 109: 312-5.

23. Mars M, Govender S, Weston A, Naicker V, Chuturgoon A. High intensity exercise: a cause of lymphocyte apoptosis? Biochem Biophys Res Commun 1998; 249: 366-70.

24. Mickleborough T, Gotshall R. Dietary components with demonstrated effectiveness in decreasing the severity of exercise-induced asthma. Sports Med 2003; 33: 671-81.

25. Nieman D. Upper respiratory tract infections and exercise. Thorax 1995; 50: 1229-31.

26. Nieman DC, Johansen LM, Lee JW, Arabatzis K. Infectious episodes in runners before and after the Los Angeles Marathon. J Sports Med Phys Fitness 1990; 30: 316-28.

27. Ostrowski K, Rohde T, Asp S, Schjerling P, Pedersen BK. Pro- and antiinflammatory cytokine balance in strenuous exercise in humans. $J$ Physiol 1999; 515: 287-91.
28. Passalacqua G, Canonica GW. Impact of rhinitis on airway inflammation: biological and therapeutic implications. Respiratory Research 2001; 2: 320-3.

29. Peters EM, Bateman ED. Ultramarathon running and upper respiratory tract infections: An epidemiological study. S Afr Med J 1983; 64: 582-4.

30. Peters EM, Goetzsche JM, Grobbelaar B, Noakes TD. Vitamin C supplementation reduces the incidence of postrace symptoms of upper-respiratory-tract infection in ultamarathon runners. Am J Clin Nutr 1993; 57: 170-4.

31. Peterson CG, Enander I, Nystrand J, Anderson AS, Nilsson L, Venge P. Radioimmunoassay of human eosinophil cationic protein (ECP) by an improved method. Establishment of normal levels in serum and turnover in vivo. Clin Exp Allergy 1991; 21: 561-7.

32. Powers SK, Howley ET. Exercise Physiology: Theory and Application to Fitness and Performance. New York: McGraw-Hill Higher Education, 2001.

33. Provost-Craig MA, Arbour KS, Sestili DC, Chabalko JJ, Ekinci E. The incidence of exercise-induced bronchospasm in competitive figure skaters. $J$ Asthma 1996; 33: 67-71.

34. Ross WD, Wilson NC. Growth and development. A stratagem for propotional growth assessment. Acta Paediatr Belg 1974; 24: 169-82.

35. Särnstrand B, Westergren-Thorsson G, Hernäs J, Peterson CGB, Venge $P$, Malmström A. Eosinophil cationic protein and transforming growth factor-A stimulates synthesis of hyaluronan and proteoglycan in human fibroblast cultures. In: Cordier LF, ed. Fifth International Colloquium on Pulmonary Fibrosis. Lyon, France: American Thoracic Society, 1988: 3988.

36. Schwellnus MP, Keissig M, Derman W, Noakes TD. Fusafungine reduces symptoms of upper respiratory tract infections (URTI) in runners after a 56 km race. Med Sci Sports Exerc 1997; 29: S296.

37. Schwellnus MP, Tune MJ, Derman EW, Noakes TD. Post ultra-marathon upper respiratory tract symptoms are not caused by an infection. Med Sci Sports Exerc 2002; 34: S168.

38. Semple SJ, Smith LL, McKune AJ, Neveling N, Wadee A. Alterations in acute-phase reactants (CRP, rheumatoid factor, complement, Factor B, and immune complexes) following an ultramarathon. South African Journal of Sports Medicine 2004; 16: 17-21 (this issue).

39. Shek PN, Shephard RJ. Physical exercise as a human model of limited inflammatory response. Can J Physiol Pharmacol 1998; 76: 589-97.

40. Shephard RJ, Rhind S, Shek PN. Exercise and the immune system. Sports Med 1994; 18: 340-69.

41. Smith LL. Overtraining, excessive exercise, and altered immunity: is this a T helper-1 versus T helper-2 lymphocyte response? Sports Med 2003; 33: $347-64$.

42. Venge $P$, Hakansson $L$. Current understanding of the role of the eosinophil granulocyte in asthma. Clin Exp Allergy 1991; 21: Suppl 3, 31-7.

43. Wardlaw AJ. Eosinophils in the 1990's: new perspectives on their role in health and disease. Postgrad Med J 1994; 70: 536-52. 